\title{
FORMAÇÃO E CONDIÇÕES DE TRABALHO DO PROFESSOR DO ENSINO MÉDIO NO BRASIL
}

\author{
TRAINING AND WORKING CONDITIONS OF HIGH SCHOOL TEACHERS IN BRAZIL \\ FORMACIÓN Y CONDICIONES DE TRABAJO DEL PROFESOR DE LA ENSEÑANZA \\ SECUNDARIA EN BRASIL
}

Gilvan Luiz Machado Costa ${ }^{1}$

Maria da Graça Nóbrega Bollmann²

\begin{abstract}
${ }^{1}$ Doutor em Educação pela UNICAMP. Docente do Programa de Pós-Graduação em Educação da Universidade do Sul de Santa Catarina (UNISUL), Tubarão, SC, Brasil.
\end{abstract}

${ }^{2}$ Doutora em Educação pela PUC/Rio. Docente do Programa de Pós-Graduação em Educação da Universidade do Sul de Santa Catarina (UNISUL), Tubarão, SC, Brasil.

Resumo: O artigo tem como objetivo compreender os limites e as perspectivas à formação inicial e às condições de trabalho dos professores do Ensino Médio no Brasil. Apresenta a discussão com base em indicadores educacionais arrolados à valorização do professor do Ensino Médio, com destaque para a Adequação da Formação Docente e Esforço Docente. Os dados expressam os limites em relação às proposições das metas 15 a 18 do Plano Nacional de Educação (2014-2024) e evidenciam desafios relacionados à elevação da formação acadêmica e melhoria das condições de trabalho do professor do Ensino Médio. Aponta a necessidade de elevar de, aproximadamente, 58\% para 100\% o percentual de professores do Ensino Médio das escolas estaduais com formação adequada. Indica que cerca de $25 \%$ dos professores têm mais de 300 alunos, que atuam nos três turnos, em duas ou três escolas e em duas ou mais etapas. Sugere que o problema da qualidade do Ensino Médio, colocado com muita intensidade no centro das discussões com a sanção da Lei 13.415/2017, não se resolverá com a flexibilização curricular proposta. A resolução demanda, além de mudanças curriculares, formação inicial e continuada dos professores, remuneração, carreira e condições de trabalho condizentes com o exercício da profissão, nos termos de uma escola de qualidade para todas e todos. Palavras-chave: Ensino Médio; Formação Inicial; Condições de Trabalho.

Abstract: The article aims to understand the limits and perspectives relating to the initial training and working conditions of High School teachers in Brazil. It presents a discussion based on educational indicators related to the valorization of High School teachers, highlighting Appropriate Teacher training and Teaching Effort. The data express limits related to the proposed goals 15 to 18 of the National Education Plan (2014-2024), and evidence challenges to increasing academic training and improving working conditions for High School teachers. This study points to a need to increase the number of teachers with appropriate training in state High Schools from around $58 \%$ at present, to $100 \%$. The study indicates that about $25 \%$ of teachers have more than 300 students, and that they work in three shifts, in two or three schools, and in two or more levels of education. It is suggested that the quality problem in High School education, which was discussed with great intensity after the sanction of Law 13.415/2017, will not be resolved by the proposed curricular flexibilization. The resolution demands, besides curriculum changes, initial and continuing training for teachers, remuneration, and career and working conditions consistent with their professional practice, ensuring a school with quality for all. Keywords: High School; Initial Training; Working Conditions. 
Resumen: Este artículo tiene como objetivo comprender los límites y las perspectivas para la formación inicial y las condiciones de trabajo de los profesores de la Enseñanza Secundaria en Brasil. Presenta la discusión basada en indicadores educacionales relacionados con la valorización del profesor de la Enseñanza Secundaria, con despegue para la Adecuación de la Formación Docente y Esfuerzo Docente. Los datos expresan límites con relación a las proposiciones de las metas 15 a 18 del Plan Nacional de Educación (2014-2024), y evidencian desafíos relacionados con la elevación de la formación académica y mejora de las condiciones de trabajo del profesor de la Enseñanza Secundaria. Apuntan la necesidad de elevar, de aproximadamente $58 \%$ para $100 \%$ los profesores de la Enseñanza Secundaria de las escuelas estaduales con formación adecuada. Indican que acerca de $25 \%$ de los profesores tienen más de 300 alumnos, que actúan y los tres turnos, en dos o tres escuelas y en dos o más etapas. Sugieren que el problema de la cualidad de la Enseñanza Secundaria, colocado con mucha intensidad en el centro de las discusiones con la Ley 13.415/2017, no se va a resolver con la flexibilidad curricular propuesta. La solución demanda, más allá de cambios curriculares, formación inicial y continuada de los profesores, remuneración, carrera y condiciones de trabajo adecuados a la profesión, en los términos de una escuela de cualidad para todas y todos.

Palabras clave: Enseñanza Secundaria; Formación Inicial; Condiciones de Trabajo.

\section{INTRODUÇÃO}

O debate sobre o Ensino Médio no Brasil nos últimos vinte e um anos, desde a promulgação da Lei 9.394, de 1996, que Ihe atribuiu estatuto de etapa da Educação Básica, tem sido intenso. As tentativas de reformulação do currículo são recorrentes e evidenciam disputas em torno dos sentidos e das finalidades do Ensino Médio. Ganha destaque no tempo presente a sanção da Lei 13.415, de 16 de fevereiro de 2017, que traz uma proposta de reforma ancorada na flexibilização curricular (KRAWCZYK; FERRETTI, 2017). A referida Lei 13.415/2017, cópia da Medida Provisória 746/2016, supervaloriza a mudança curricular e a apresenta como capaz de corrigir a dívida social com o Ensino Médio. Para Motta e Frigotto (2017, p. 358), as questões-chave da reforma proposta apontam para "investir no capital humano visando maior produtividade; modernizar a estrutura curricular, flexibilizando por áreas de conhecimento; e melhorar os resultados do desempenho escolar".

A referida legislação coloca holofotes sobre a política curricular do Ensino Médio e retira do centro das discussões a ausência de políticas públicas que promovam a qualidade social ${ }^{1}$ desta etapa da Educação Básica. Destaca-se como fundamental nesse processo a valorização dos professores, contemplada no Plano Nacional de Educação (PNE), aprovado pela Lei 13.005/2014, nas suas metas 15 a 18. Ao mesmo tempo, Oliveira (2014) aponta que a questão docente expressa, ao longo das metas e das estratégias do PNE, as contradições do debate educacional. Trata-se de um amplo e complexo debate. Todavia, a questão da formação inicial e das condições de trabalho são fatores decisivos à materialização de um currículo amplo, pautado na formação humana integral² de todos, mormente os jovens de 15 a 17 anos.

Considera-se professor o profissional da educação que possui licenciatura, o que suscita apresentar elementos da formação inicial do professor do Ensino Médio. Ao mesmo tempo, ganha proeminência problematizar a questão das condições de trabalho ${ }^{3}$, com destaque às relações de emprego, que se constituem fator decisivo à atratividade da profissão docente 
(OLIVEIRA, 2016). A partir dessas reflexões, problematizou-se no presente artigo: quais os limites e as perspectivas à formação inicial e às condições de trabalho dos professores do Ensino Médio que atuam nas escolas estaduais no Brasil? Buscou-se conhecer aspectos da formação inicial dos professores do Ensino Médio ${ }^{4}$ e, posteriormente, as condições de trabalho, com realce a elementos da jornada de trabalho e sua relação com aspectos da carreira.

Os subsídios empíricos para a referida problematização foram buscados no Censo Escolar da Educação Básica, sobretudo, nos indicadores educacionais Adequação da Formação Docente e Esforço Docente, e nas metas 15 a 18 do PNE. Os dados foram cotejados com parte da produção bibliográfica relacionada à temática do estudo. A análise pautou-se nas seguintes categorias de conteúdo: formação inicial do professor do Ensino Médio e condições de trabalho do professor do Ensino Médio. Com o entendimento de tornar a última etapa da Educação Básica de fato um direito de cidadania (KRAWCZYK, 2014), na análise buscou-se superar a mera descrição do objeto de estudo e avançar na sua compreensão. Compreender as políticas de valorização dos professores do Ensino Médio sugere, segundo Mainardes (2014), apreender os processos e as estruturas, ou seja, os seus condicionantes mais gerais.

\section{FormaÇão INICIAL do PROFESSOR DO ENSINO MÉdIO}

Recentemente, o acesso às etapas da Educação Básica foi contemplado na Lei 13.005/2014, que aprovou o PNE para o decênio 2014-2024. Ao Ensino Médio, destaca-se, na meta 3, oportunizar até 2024 a 85\% dos jovens pertencentes ao grupo de idade 15 a 17 anos a matrícula no Ensino Médio, etapa escolar adequada à mencionada faixa etária.

O proposto justifica-se quando se constata que aproximadamente 4,3 milhões de jovens pertencentes ao grupo de 15 a 17 anos não estavam matriculados no Ensino Médio em 2015. Revela, de um lado, a sistemática negação do acesso e da permanência no Ensino Médio; e, por outro lado, o desafio dos entes federados para levar a cabo o que esta meta do PNE fixa para o atendimento até 2024. Ao considerar que o lugar do jovem pertencente ao grupo de idade entre 15 e 17 anos é, preferencialmente, na última etapa da Educação Básica, e, com base em Saviani (2013), sugere-se ao Estado brasileiro assumir o dever correlato de garantir a todos esse direito.

Os números do Ensino Médio no Brasil sugerem, por parte do Estado, "elevado investimento; o desenvolvimento de um currículo amplo e articulado de caráter geral; exige professores qualificados e bem pagos, espaço físico adequado" (KÜENZER, 2010, p. 864). Evidenciam que as políticas públicas educacionais de acesso e permanência se alinhem às de valorização dos profissionais da educação. Tal entendimento encontra-se expresso na Lei 13.005/2014 ao trazer, em seu artigo $2^{\circ}$, dentre as diretrizes, a universalização do atendimento escolar; a melhoria da qualidade da educação; a valorização dos(as) profissionais da educação.

Em um contexto de mais estudantes e, consequentemente, mais professores, ganham centralidade as metas do PNE relacionadas à valorização dos profissionais da educação, compreendida como envolvendo de forma articulada formação inicial e continuada, condições de trabalho, remuneração e carreira (CONAE, 2014). Diante do exposto, vale problematizar a 
formação acadêmica dos professores do Ensino Médio, apresentada na Tabela 1.

Tabela 1 - Professores do Ensino Médio do Brasil segundo a formação acadêmica - 2013/2016

\begin{tabular}{l|c|c|c|c|c|c|c}
\hline Ano & Total & Formação superior & $\mathbf{( \% )}$ & Com $^{5}$ licenciatura & $\mathbf{( \% )}$ & Sem & $\mathbf{( \% )}$ \\
& & & & & & & \\
$\mathbf{2 0 1 3}$ & 509.403 & 472.450 & 92,8 & 435.369 & 85,5 & 37.081 & 7,3 \\
$\mathbf{2 0 1 4}$ & 524.315 & 487.321 & 92.9 & 454.644 & 86,7 & 32.677 & 6,2 \\
$\mathbf{2 0 1 5}$ & 522.826 & 484.857 & 92,7 & 449.781 & 86,0 & 35.076 & 6,7 \\
$\mathbf{2 0 1 6}$ & 519.883 & 484.785 & 93,2 & 448.890 & 86,3 & 35.895 & 6,9 \\
\hline
\end{tabular}

Fonte: BRASIL (2016a)

Percebe-se, ao longo do interregno 2013-2016, um percentual expressivo de sujeitos que lecionam no Ensino Médio com Ensino Superior. Verifica-se uma acomodação ao redor dos 93,0\% que possuem graduação. Trata-se de números interessantes, por outro lado, a falta de professores com formação adequada para lecionar nas escolas de Ensino Médio é evidente. Entende-se que não basta cursar um determinado curso superior para ser professor. Considerase professor do Ensino Médio os que possuem como formação acadêmica uma licenciatura.

Os dados apontam para a manutenção de $87 \%$ dos professores do Ensino Médio com licenciatura ou com complementação pedagógica. Expressam a possibilidade de $13 \%$ lecionarem sem ser professor por não estarem habilitados para exercer a docência. ${ }^{6}$ Importa que todos os professores do Ensino Médio sejam licenciados. Com base na Lei de Diretrizes e Bases da Educação 9.394/96 (LDB), sem a licenciatura não são considerados professores, como dispõe no inciso I do artigo 61 e no caput do artigo 62:

A formação de docentes para atuar na educação básica far-se-á em nível superior, em curso de licenciatura, de graduação plena, em universidades e institutos superiores de educação, admitida, como formação mínima para o exercício do magistério na educação infantil e nos 5 (cinco) primeiros anos do ensino fundamental, a oferecida em nível médio na modalidade normal. (BRASIL, 1996).

Tal compreensão se amplia quando se considera, entre outros fatores, segundo Küenzer (2011, p. 671), "a desigualdade da distribuição da qualificação entre as disciplinas, fato que vem sendo reiteradamente apontado nas últimas décadas. Assim, apenas $53 \%$ dos professores que atuam no ensino médio têm formação compatível com a disciplina que lecionam". Neste contexto, baseia-se o proposto pela meta 15 do PNE que enuncia:

[...] garantir, em regime de colaboração entre a União, os Estados, o Distrito Federal e os Municípios, no prazo de 1 (um) ano de vigência deste PNE, política nacional de formação dos profissionais da educação de que tratam os incisos I, II e III do caput do art. 61 da Lei no 9.394, de 20 de dezembro de 1996, assegurado que todos os professores e as professoras da educação básica possuam formação específica de nível superior, obtida em curso de licenciatura na área de conhecimento em que atuam. (BRASIL, 2014).

Ganha visibilidade o professor com formação na disciplina que leciona. Neste âmbito, com intuito de contribuir com a materialização da meta 15, o Instituto Nacional de Estudos e Pesquisas Educacionais Anísio Teixeira (INEP) constrói o Indicador de adequação da formação do docente da educação básica. Tendo por referência os documentos legais, distribuiu o docente, com base em sua formação, em cinco grupos, conforme mostra o Quadro 1. 
Quadro 1 - Categorias de adequação da formação dos docentes em relação à disciplina que leciona

\begin{tabular}{|c|c|}
\hline Grupo & Descrição \\
\hline 01 & $\begin{array}{r}\text { Docentes com formação superior de licenciatura na mesma disciplina que } \\
\text { lecionam ou bacharelado na mesma disciplina com curso de complementação } \\
\text { pedagógica concluído. }\end{array}$ \\
\hline 02 & $\begin{array}{r}\text { Docentes com formação superior de bacharelado na disciplina correspondente, } \\
\text { mas sem licenciatura ou complementação pedagógica. }\end{array}$ \\
\hline 03 & $\begin{array}{r}\text { Docentes com licenciatura em área diferente daquela que leciona, ou com } \\
\text { bacharelado nas disciplinas da base curricular comum e complementação } \\
\text { pedagógica concluída em área diferente daquela que leciona. }\end{array}$ \\
\hline 04 & \begin{tabular}{c} 
Docentes com outra formação superior não considerada nas categorias anteriores. \\
\hline 05
\end{tabular} \\
\hline
\end{tabular}

Fonte: BRASIL (2016b)

Ao considerar o enunciado da meta 15, a proporção de docentes no grupo 1 poderia ser a métrica utilizada para acompanhá-la, por ser "formado por docentes que atuam na mesma área de atuação de sua formação inicial, relação apropriada entre docência e formação do docente segundo os dispositivos legais" (BRASIL, 2016b, p. 5). Com base no referido indicador, pode-se constatar na Tabela 2 que, no quadriênio 2013-2016, a média foi de 41,7\% dos professores do Ensino Médio da dependência administrativa estadual sem formação para compor o grupo 1 nas escolas. Trata-se de profissionais que não possuíam licenciatura na mesma disciplina que lecionam, ou bacharelado na mesma disciplina com curso de complementação pedagógica concluído.

Tabela 2 - Percentual de docentes no Ensino Médio por grupo do indicador de adequação da formação docente, segundo dependência administrativa estadual - Brasil - 2013-2016

\begin{tabular}{ccccccc}
\hline Ano & Abrangência & Grupo 1 & Grupo 2 & Grupo 3 & Grupo 4 & Grupo 5 \\
\hline $\mathbf{2 0 1 3}$ & Estadual & 56,9 & 3,9 & 25,5 & 7,0 & 6,7 \\
$\mathbf{2 0 1 4}$ & Estadual & 58,7 & 2,7 & 25,5 & 6,7 & 6,4 \\
$\mathbf{2 0 1 5}$ & Estadual & 58,0 & 3,1 & 25,6 & 6,8 & 6,5 \\
$\mathbf{2 0 1 6}$ & Estadual & 59,7 & 3,1 & 24,8 & 6,8 & 5,6 \\
\hline
\end{tabular}

Fonte: BRASIL (2016)

Os dados mostram que, para dar conta da meta 15, é necessário ampliar significativamente o número de professores com licenciatura nas disciplinas sob sua responsabilidade. Ao longo do quadriênio, verificou-se um tímido aumento de 2,8\% de professores pertencentes ao Grupo 1 e expressa "o grande desafio de garantir a formação, em nível superior" (DOURADO, 2016, p. 39), preconizado na referida meta. O autor destaca a necessidade de políticas para a formação que superem a forte presença de professores com licenciatura em uma determinada disciplina ou área e que "atuam em área distinta, muitas das vezes para complementar a carga horária".

O campo educacional apresenta-se, no segundo ano de vigência do PNE, preocupante: mesmo com a centralidade atribuída à educação escolar, "faltam" professores habilitados para 
lecionar nas escolas estaduais do Ensino Médio. Este contexto já havia sido constatado por Küenzer (2011, p. 671), que apontava "a necessidade do esforço intensivo na formação inicial de professores". Mais de 40\% dos professores das escolas estaduais não estão em conformidade com a meta 15. Situação que se acentua com as "metas de expansão propostas pelo PNE, relativas à universalização do atendimento a toda a população de 15 a 17 anos e à elevação da taxa líquida de matrículas para 85\% nesta faixa etária".

Para além da escassez de professores, questiona-se a qualidade da formação docente (KÜENZER, 2011). As licenciaturas não podem desconsiderar a juventude que frequenta e que frequentará a última etapa da Educação Básica. É importante que o futuro professor do Ensino Médio mergulhe "no universo da escola e da sala de aula e que o fortaleça por meio de uma sólida formação teórica e prática" (SILVA, 2015, p. 72). Esta perspectiva está presente nas Diretrizes Curriculares Nacionais para a formação inicial em nível superior (cursos de licenciatura, cursos de formação pedagógica para graduados e cursos de segunda licenciatura) e para a formação continuada (BRASIL, 2015). Com base nas referidas Diretrizes, Dourado (2015, p. 308) propõe que, na formação inicial, sejam previstos "conhecimentos pedagógicos, compreendendo a articulação entre estudos teórico-práticos, investigação e reflexão crítica, aproveitamento da formação e experiências anteriores em instituições de ensino".

Neste âmbito, destaca-se a estratégia 15.6 da meta 15 que aponta:

Promover a reforma curricular dos cursos de licenciatura e estimular a renovação pedagógica, de forma a assegurar o foco no aprendizado do (a) aluno (a), dividindo a carga horária em formação geral, formação na área do saber e didática específica e incorporando as modernas tecnologias de informação e comunicação [...]. (BRASIL, 2014).

A ausência de professores habilitados e a qualidade da formação justificam-se, segundo Küenzer (2011, p. 672), pela baixa atratividade da carreira docente. A autora sugere que "a política de formação só tem sentido quando integrada à estruturação da carreira docente, à política salarial que assegure a dignidade do professor e à garantia de condições adequadas de trabalho". Importa que as políticas de formação se articulem para garantir "[...] maior tempo remunerado para os docentes nas escolas, permitindo o desenvolvimento de maiores vínculos com seu trabalho e, logo, maior tempo de dedicação à educação desses jovens" (OLIVEIRA, 2010, p. 275). Tais compreensões são corroboradas por Saviani (2011, p. 16) ao enfatizar que não é possível "equacionar devidamente o problema da formação dos professores sem enfrentar simultaneamente a questão das condições de exercício do trabalho docente. Isso porque, de fato, esses dois aspectos se articulam e se relacionam na forma de ação recíproca".

Retomar a expansão da matrícula do Ensino Médio implica ampliar o número de professores com licenciatura na disciplina que lecionam. Demanda, também, acento nas demais dimensões da valorização dos profissionais da educação. Sugere, de acordo com Küenzer (2011, p. 675), "efetivo investimento em políticas que integrem formação, carreira, remuneração e condições dignas de trabalho". Condições necessárias para enfrentar uma histórica realidade de escassez, inadequação e "desprofissionalização" do professor, "com seus severos impactos sobre a qualidade do ensino médio, cujas matrículas decrescem a cada ano, assim como não melhoram os indicadores de permanência e de sucesso". 
O problema da "falta7" de professores do Ensino Médio pode estar relacionado à carreira, ao baixo nível de remuneração e ao número excessivo de turnos, turmas, aulas e alunos. Destaca-se a centralidade das condições de trabalho, considerada essencial quando se discute a valorização dos profissionais da educação (CONAE, 2014).

\section{Condições de trabalho do PROFESSOR do EnSino Médio}

Vislumbra-se a materialização das metas 3 e 15 do PNE. Ao mesmo tempo, para além da ampliação do acesso e da adequada formação inicial, advoga-se que sejam oferecidas a todos os jovens "condições educativas para o aprendizado intelectual, o qual pressupõe denso tempo de leitura, laboratórios, espaço de lazer, arte e cultura" (FRIGOTTO; CIAVATTA, 2011, p. 620). Estas demandas trazem novos desafios aos docentes que, segundo Oliveira (2014, p. 451), "devem também estar em condições de desenvolver a autonomia dos alunos e o seu interesse em seguir aprendendo ao longo da vida". Para enfrentar este desafio, as condições oferecidas aos docentes "não são muitas vezes minimamente adequadas em termos materiais, menos ainda em dimensões subjetivas, que precisam ser cada vez mais observadas" (OLIVEIRA, 2014, p. 451). No âmbito das condições de trabalho interessa as relações de emprego, com destaque ao tipo de vínculo, à jornada de trabalho, à remuneração e à formação, vinculados à carreira (PINTO; DUARTE; VIEIRA, 2012).

No PNE, aspectos relacionados às condições de trabalho estão diluídos nas diferentes metas e estratégias. A meta $18^{8}$, em sua estratégia 18.1 , destaca a preocupação com o vínculo do professor ao propor:

Estruturar as redes públicas de educação básica de modo que, até o início do terceiro ano de vigência deste PNE, noventa por cento, no mínimo, dos respectivos profissionais do magistério [...] sejam ocupantes de cargos de provimento efetivo e estejam em exerć́cio nas redes escolares a que se encontrem vinculados. (BRASIL, 2014).

Por outro lado, o ingresso do professor do Ensino Médio na carreira docente ainda está muito distante do preconizado na referida estratégia. A Tabela 3 demonstra o número de professores efetivos do Ensino Médio da rede pública de ensino.

Tabela 3 - Professores do Ensino Médio público efetivos, segundo as dependências administrativas - Brasil - 2013/2016

\begin{tabular}{|c|c|c|c|c|c|c|}
\hline Ano & Total & Efetivos & Federal & Estadual & Municipal & Total $\%$ \\
\hline 2013 & 425.940 & 301.996 & 14.490 & 284.351 & 4.262 & 70,9 \\
\hline 2014 & 439.561 & 309.603 & 15.640 & 291.254 & 3.732 & 70.9 \\
\hline 2015 & 438.946 & 304.641 & 17.903 & 284.174 & 3.525 & 69,4 \\
\hline 2016 & 435.049 & 299.136 & 20.528 & 276.087 & 3.409 & 68,6 \\
\hline
\end{tabular}

Fonte: Brasil (2016a)

Os dados sugerem que aproximadamente $30 \%$ dos professores do Ensino Médio público não são concursados, possuem contrato, em sua grande maioria temporário, além do terceirizado ou celetista. Ao apresentar um número expressivo de professores com contratos temporários de forma persistente, evidencia-se, com base em Oliveira (2006, p. 216), certa precarização nos aspectos concernentes às relações de emprego oferecidas. Os contratos temporários são desprovidos de garantias trabalhistas e previdenciárias e, por não assegurarem 
os mesmos direitos e garantias dos professores efetivos, tornam "cada vez mais agudo o quadro de instabilidade e precariedade do emprego".

Uma carreira estável pode tornar a profissão docente mais atraente ao possibilitar, segundo Camargo et al. (2006, p. 260), "uma maior segurança para a realização de seu trabalho, uma vez que não estaria sujeito a demissões ao final de licenças, de contratos ou ao final do ano". Com base nos autores, infere-se que a estabilidade trabalhista, o ingresso a uma carreira docente definida e a realização de seu trabalho com maior segurança sugerem melhores perspectivas às condições de oferta de um Ensino Médio de qualidade. Contraditoriamente, não pertencer ao quadro dos efetivos exclui estes professores "da complexidade da dinâmica da escola e das relações no interior da mesma, devido sua transitoriedade, limitam a sua participação e envolvimento na construção do projeto educativo da escola" (CAMARGO et al., 2006, p. 260).

O número expressivo de professores do Ensino Médio público brasileiro com contratos temporários pode ser "explicado" pela dimensão econômica. Há uma estreita vinculação entre a forma de contratação e a remuneração dos profissionais da educação. Os professores temporários têm menores remunerações. No Brasil não se remuneram adequadamente os professores efetivos, menos ainda os temporários (OLIVEIRA, 2006).

Valorizar os professores do Ensino Médio seria a natural opção política de um Estado (União, Estados da Federação e Distrito Federal) realmente comprometido com a universalização da Educação Básica com qualidade (KÜENZER, 2010). Ao considerar os 414.865 professores que lecionam nas escolas estaduais do Brasil (BRASIL, 2016a), espera-se que sejam licenciados, efetivos e possuam condições de trabalho adequadas, como sugere a Lei 11.738/08 (BRASIL, 2008), que instituiu o Piso Salarial Profissional Nacional (PSPN) para os profissionais do magistério público da Educação Básica com formação em nível médio, na modalidade Normal, para jornada de, no máximo, 40 (quarenta) horas semanais. Na composição da jornada de trabalho, destaca-se o limite máximo de 2/3 (dois terços) da carga horária para o desempenho das atividades de interação com os educandos.

Levantamento realizado em 2016 pela Confederação Nacional dos Trabalhadores em Educação (CNTE) explicita que a referida lei não é cumprida nos quesitos Piso e Jornada Extraclasse por seis dos estados da federação: Amazonas, Goiás, Maranhão, Paraíba, Rio Grande do Sul e São Paulo. Ressalta-se também que a aplicação da Lei do Piso tem registrado prejuízos às carreiras do magistério, ofendendo, assim, o dispositivo constitucional (art. 206, V), que preconiza a valorização dos profissionais da educação por meio de planos de carreira que atraiam e mantenham os trabalhadores nas escolas públicas, contribuindo para a melhoria da qualidade da educação (CNTE, 2016). O cumprimento da Lei 11.738/08 remete à meta 17, que propõe "valorizar os (as) profissionais do magistério das redes públicas de educação básica de forma a equiparar seu rendimento médio ao dos (as) demais profissionais com escolaridade equivalente, até o final do sexto ano de vigência deste PNE". Para Masson (2016, p. 161), "a equiparação salarial do professor com as demais profissões é condição indispensável para a atratividade e permanência na carreira, pois é a questão que mais determina a escolha dos jovens, embora isso não seja suficiente". A autora destaca que a remuneração dos professores tem melhorado com a aprovação do PSPN. Por outro lado, aponta que muitos estados da 
federação têm considerado o valor mínimo como se fosse o máximo.

As disparidades estaduais no que tange à valorização dos professores sugerem a construção de um Sistema Nacional de Educação (SNE), com ampla colaboração dos estados da federação para usar da prerrogativa de sua autonomia para valorizar seus professores. A inexistência de um SNE permite que as políticas educacionais se movimentem nos diferentes estados, por exemplo, com planos de carreira e remunerações distintas entre os professores; infraestrutura instalada com padrões diferentes; e propostas pedagógicas diversas (GOUVEIA; PINTO; CORBUCCI, 2011).

Este contexto adverso manifesta-se na rotatividade de professores, na multiplicidade de vínculos empregatícios e na decorrente extensão da jornada de trabalho docente, opondo-se à qualidade social do Ensino Médio brasileiro. A valorização salarial com a garantia de satisfação das necessidades básicas a partir de seu salário mensal recebido da rede de ensino a que está vinculado pode permitir, por exemplo, que os professores do Ensino Médio se dediquem a uma determinada escola e com tempo disponível para elaborar suas aulas. Para Saviani (2011, p. 16), a qualidade do trabalho pedagógico eleva-se com "jornada de trabalho de tempo integral em uma única escola com tempo para aulas, preparação de aulas, orientação de estudos dos alunos, participação na gestão da escola e reuniões de colegiados e atendimento à comunidade".

Nesse campo, o INEP constrói o indicador Esforço Docente, que mensura o esforço empreendido pelos docentes da Educação Básica brasileira no exercício de sua profissão (BRASIL, 2016c). Considera o número de turnos de trabalho, escolas e etapas de atuação, além da quantidade de alunos atendidos na Educação Básica, e articula-se à jornada de trabalho. $O$ Quadro 2 apresenta a descrição dos níveis baseada na distribuição empírica das variáveis.

Quadro 2 - Categorias de adequação da formação dos docentes em relação à disciplina que leciona

\begin{tabular}{|c|c|}
\hline Nível & Descrição \\
\hline 01 & Docente que tem até 25 alunos e atua em um único turno, escola e etapa. \\
\hline 02 & $\begin{array}{c}\text { Docente que tem entre 25 e } 150 \text { alunos e atua em um único turno, escola e etapa. } \\
\text { Docente que tem entre 25 e 300 alunos e atua em um ou dois turnos em uma } \\
\text { única escola e etapa. }\end{array}$ \\
\hline 03 & $\begin{array}{r}\text { Docente que tem entre 50 e } 400 \text { alunos e atua em dois turnos, em uma ou duas } \\
\text { escolas e em duas etapas. }\end{array}$ \\
\hline 04 & $\begin{array}{r}\text { Docente que tem mais de 300 alunos e atua nos três turnos, em duas ou três } \\
\text { escolas e em duas etapas ou três etapas. }\end{array}$ \\
\hline 06 & $\begin{array}{c}\text { Docente que tem mais de 400 alunos e atua nos três turnos, em duas ou três } \\
\text { escolas e em duas etapas ou três etapas. }\end{array}$ \\
\hline
\end{tabular}

Fonte: BRASIL (2016c)

Não obstante a tentativa de abarcar as duas últimas etapas da Educação Básica, considerase que o indicador Esforço Docente apresenta limites para a compreensão do Ensino Médio. Qual nível poderia ser a métrica utilizada para acompanhar as estratégias do PNE relacionadas aos aspectos das condições de trabalho do Ensino Médio? No entanto, os níveis 05 e 06 expressam claramente a intensificação do trabalho docente. ${ }^{9}$ 
Os dados de 2016 apresentados na Tabela 4 mostram que 16,7\% dos professores do Ensino Médio que lecionam nas escolas estaduais no Brasil têm mais de 300 alunos e atuam nos três turnos, em duas ou três escolas e em duas etapas ou três etapas. Um esforço docente maior é dispendido por 8,1\% que trabalham com mais de 400 alunos e atuam nos três turnos, em duas ou três escolas e em duas etapas ou três etapas.

Tabela 4 - Percentual de docentes que atuam no Ensino Médio por níveis do indicador de esforço docente,

segundo localização e dependência administrativa estadual - Brasil - 2013-2016

\begin{tabular}{lccccccc}
\hline Ano & Abrangência & Nível 1 & Nível 2 & Nível 3 & Nível 4 & Nível 5 & Nível 6 \\
\hline $\mathbf{2 0 1 3}$ & Estadual & 0,6 & 7,1 & 21,8 & 45,0 & 17,1 & 8,4 \\
$\mathbf{2 0 1 4}$ & Estadual & 0,7 & 7,5 & 22,4 & 44,9 & 16,4 & 8,1 \\
$\mathbf{2 0 1 5}$ & Estadual & 0,8 & 7,4 & 22,0 & 45,3 & 16,7 & 7,8 \\
$\mathbf{2 0 1 6}$ & Estadual & 0,9 & 7,2 & 21,5 & 45,6 & 16,7 & 8,1 \\
\hline
\end{tabular}

Fonte: BRASIL (2016c)

Ressalta-se que, no interregno 2013 a 2016, aproximadamente 25\% dos professores do Ensino Médio das escolas estaduais concentravam-se nos níveis 05 e 06, o que revela uma jornada extensa e intensa. Trabalhar em mais de uma escola, em três turnos com muitos alunos de diferentes etapas da Educação Básica faz parte do cotidiano de uma parcela expressiva dos professores da última etapa da Educação Básica, os quais lecionam nas escolas estaduais no Brasil. Os dados explicitam a persistência da grande concentração de professores com mais de 300 alunos e atuando nos três turnos, em duas ou três escolas e em duas etapas ou três etapas.

A dedicação a uma escola e jornadas não exaustivas parecem não ser uma realidade dos professores do Ensino Médio. Por outro lado, sua conquista resulta, segundo Camargo et al. $(2006,273)$, "numa satisfação que, além de promover condições para uma oferta de ensino de qualidade, evita prejuízos à saúde do trabalhador e permite tempo para aqueles interessados em processos complementares de qualificação profissional". Como contraponto a uma jornada de trabalho com muitas escolas, turnos e alunos, destaca-se a estratégia 17.3 contida no PNE que incorpora as conquistas da Lei 11.738 :

Implementar, no âmbito da União, dos Estados, do Distrito Federal e dos Municípios, planos de Carreira para os (as) profissionais do magistério das redes públicas de educação básica, observados os critérios estabelecidos na Lei $\mathrm{n}^{\circ} 11.738$, de 16 de julho de 2008, com implantação gradual do cumprimento da jornada de trabalho em um único estabelecimento escolar. (BRASIL, 2014).

A materialização do proposto nas metas do PNE poderá representar maior valorização social do professor (MASSON, 2016). Considera-se a complexidade do currículo do Ensino Médio com treze componentes curriculares distribuídos em vinte e cinto aulas semanais e os limites de um professor cumprir sua carga horária em um único estabelecimento. Todavia, com base em Camargo et al. (2016), a construção da possibilidade de os professores das escolas estaduais do Ensino Médio dedicarem-se a somente uma escola está vinculada a todas as dimensões da valorização dos profissionais da educação. Em outras palavras, articula-se com a formação, a carreira, a remuneração e as condições de trabalho.

A discussão sobre aspectos das condições de trabalho vincula-se à qualidade social do Ensino Médio. Alves e Pinto (2011, p. 633) lembram que a conquista de uma escola pública 
de qualidade para todos passa por uma adequada jornada de trabalho que contemple "hora de trabalho extraclasse a ser cumprida na escola e estimule a dedicação exclusiva à docência e, preferencialmente, em uma única escola". A esse componente os autores incorporam a remuneração adequada. Para esses autores, equacionados esses dois componentes, "as condições necessárias, embora não suficientes, para um salto de qualidade na educação básica estarão dadas".

No âmbito do Ensino Médio, os indicadores Adequação da Formação e Esforço Docente, visitados, mostraram que as escolas estaduais passaram e ainda passam por um intenso "processo de massificação barata". Ao mesmo tempo, como possiblidades, na perspectiva do Ensino Médio com qualidade social (KÜENZER, 2010), sem desconsiderar suas vicissitudes, enfatiza-se o PNE, que aponta nas metas que tratam da valorização dos profissionais da educação perspectivas virtuosas também para a última etapa da Educação Básica.

As mudanças no Ensino Médio não podem ignorar "que as escolas não possuem as condições básicas de funcionamento institucional nem do exercício do trabalho dos professores, oferecendo aos estudantes condições dignas de aprendizagem" (KRAWCZYK; FERRETTI, 2017, p. 38). A reforma contida na Lei 13.415/2017 silencia, em aspectos absolutamente indispensáveis, a qualidade social do Ensino Médio, que reivindica uma formação integral. Com acento na proposta de flexibilização curricular, não oferece um caminho na direção da referida formação. Ignora que sua conquista suscita um "contexto em que a qualidade da formação docente e o prestígio social dos professores estão consolidados" (MORAES, 2017, p. 424).

\section{ConsideraçõES}

Neste artigo, procurou-se mostrar aspectos da formação inicial e das condições de trabalho do professor do Ensino Médio das escolas estaduais e os desafios à materialização das metas 15 a 18. Ao considerar o número crescente de professores nos últimos anos e o contingente de 414.865 em 2016, os indicadores educacionais visitados revelam entraves, avanços e desafios relacionados à valorização dos profissionais que lecionam no Ensino Médio no Brasil.

No âmbito da formação, os dados mostram a dimensão do esforço para materializar a meta 15 no PNE. No que diz respeito à escolaridade, ressalta-se o percentual expressivo de professores com formação em nível superior. Por outro lado, ao desagregar os dados relacionados à formação inicial, destacam-se limites quantitativos, mormente, da dependência administrativa estadual, expressos pelo indicador Adequação da Formação Docente. Evidenciam a necessidade de elevar de, aproximadamente, 58\% para 100\% o percentual de professores do Ensino Médio das escolas estaduais com formação superior de licenciatura na mesma disciplina que leciona, ou bacharelado na mesma disciplina com curso de complementação pedagógica.

Da mesma forma, no domínio das condições de trabalho, os dados apontaram que o Ensino Médio convive com professores nas escolas estaduais não concursados, que trabalham em muitas escolas, com muitas turmas, alunos, etapas e turnos. O estudo sugere que as condições de trabalho no Ensino Médio são desiguais, verificadas, por exemplo, em redes 
estaduais de ensino que sequer cumprem a Lei 11.738/2008 nos quesitos vencimento básico e carga horária. Realça-se, mesmo com os limites do indicador Esforço Docente, que 1/4 dos professores das escolas estaduais têm mais de 300 alunos e atua nos três turnos, em duas ou três escolas e em duas etapas ou mais etapas.

O Brasil tem uma grande dívida com os profissionais da educação, particularmente no que se refere à sua valorização. A concretização de grande parte das metas do PNE envolve a valorização dos profissionais da Educação Básica e o compromisso com elas é fundamental. O Ensino Médio com qualidade social só será materializado com a efetiva valorização dos profissionais da educação, consubstanciada na formação, na remuneração, na carreira e nas condições de trabalho adequadas. Somente com todos os professores valorizados e prestigiados, e com sólida formação teórica, pode-se vislumbrar a garantia a todos os jovens brasileiros do direito social à conclusão do Ensino Médio.

Considera-se também fundamental a institucionalização de um SNE e da aplicação de 10\% do PIB em educação pública previstos no PNE. Com esta compreensão, faz-se necessário, por exemplo, ampliar a vinculação constitucional de recursos para a educação. A Constituição Federal estabelece que a União invista um mínimo de $18 \%$ da receita resultante de impostos em educação, e estados e municípios, 25\%.

A materialização do PNE sugere mais recursos financeiros para a educação até atingir $10 \%$ do PIB e não o contrário. A gestão e o financiamento da educação, no âmbito do estabelecido na Lei 13.005/2014, constituem-se em elementos articuladores de um esforço coletivo dos entes federados na materialização das metas do PNE, com destaque às relacionadas ao professor do Ensino Médio das escolas estaduais e sua valorização. O problema da qualidade social do Ensino Médio, colocado com muita intensidade no centro das discussões com a sanção da Lei 13.415/2017, não se resolverá com a flexibilização curricular proposta. A resolução demanda, além de mudanças curriculares, formação inicial e continuada dos professores, remuneração, carreira e condições de trabalho condizentes com o exercício da profissão dos professores que atuam no Ensino Médio, nos termos de uma escola de qualidade para todas e todos.

\section{REFERÊNCIAS}

ALVES, T.; PINTO, J. M. R. Remuneração e características do trabalho docente no Brasil: um aporte. Cadernos de Pesquisa, São Paulo, v. 41, p. 606-639, 2011.

BRASIL. Lei de Diretrizes e Bases da Educação Nacional. Lei nº 9.394 de 20 de dezembro de 1996.

Lei $n^{\circ} 11.738$, de 16 de julho de 2008. Regulamenta a alínea "e" do inciso III do caput do art. 60 do Ato das Disposições Constitucionais Transitórias, para instituir o piso salarial profissional nacional para os profissionais do magistério público da educação básica. 2008.

Lei no 13.005, de 25 de junho de 2014. Aprova o Plano Nacional de Educação - PNE e dá outras providências. Diário Oficial da União, Brasília, DF, 2014.

Conselho Nacional de Educação. Diretrizes Curriculares Nacionais para a formação inicial em nível superior (cursos de licenciatura, cursos de formação pedagógica para graduados e cursos de 
segunda licenciatura) e para a formação continuada. Resolução CNE/CP n. 02/2015, de $1^{\circ}$ de julho de 2015. Brasília, 2015.

Ministério da Educação. Instituto Nacional de Estudos e Pesquisas Educacionais. Censo Escolar da Educação Básica, 1995 a 2015. Brasília: MEC/INEP, 2016a.

Indicador Adequação da Formação Docente da educação básica. Instituto Nacional de Estudos e Pesquisas Educacionais Anísio Teixeira Diretoria de Estatísticas Educacionais. Nota Técnica n 020/2014. Brasília, 2016b.

. Indicador de Esforço Docente. Instituto Nacional de Estudos e Pesquisas Educacionais Anísio Teixeira Diretoria de Estatísticas Educacionais. Nota Técnica nº 039/2014. Brasília, 2016c.

. Lei $n^{\circ} 13.415$, de 16 de fevereiro de 2017. Institui a Política de Fomento à Implementação de Escolas de Ensino Médio em Tempo Integral. Brasília, DF, 2017.

CAMARGO, R. B. de; et al. Condições de trabalho docente, ensino de qualidade e custo-aluno-ano. Revista Brasileira de Política e Administração da Educação, Goiânia, v. 22, p. 253-276, 2006.

CNTE. Confederação Nacional dos Trabalhadores em Educação. Tabela de Vencimentos. Brasília, 2016.

CONAE. Conferência Nacional de Educação: documento - referência /elaborado pelo Fórum Nacional de Educação. Brasília: Ministério da Educação, Secretaria Executiva Adjunta, 2010.

. Conferência Nacional de Educação: documento - referência / elaborado pelo Fórum Nacional de Educação. Brasília: Ministério da Educação, Secretaria Executiva Adjunta, 2014.

DOURADO, L. F. Diretrizes curriculares nacionais para a formação inicial e continuada dos profissionais do magistério da educação básica: concepções e desafios. Educação e sociedade, Campinas, v. 36, p. 299324, 2015.

- Valorização dos profissionais da educação Desafios para garantir conquistas da democracia. Revista Retratos da Escola, Brasília, v. 10, p. 37-56, 2016.

FÓRUM NACIONAL DE EDUCAÇÃO. Conae 2018: Conferência Nacional de Educação: documento referência. Fórum Nacional de Educação. Brasília, 2017.

FRIGOTTO, G.; CIAVATTA, M. Perspectivas sociais e políticas da formação de nível Médio: avanços e entraves nas suas modalidades. Educação e Sociedade, Campinas, v. 32, n. 116, p. 619-638, jul./set./2011.

GOUVEIA, A. B; PINTO, J. M. R.; CORBUCCI, P. R. (Orgs.). Federalismo e políticas educacionais na efetivação do direito à educação. Brasília: IPEA, 2011. v. 1. 227 p.

KRAWCZYK, N. Ensino Médio: empresários dão as cartas na escola pública. Educação \& Sociedade, v. 35, p. 21-42, 2014.

KRAWCZYK, N.; FERRETTI, C. J. Flexibilizar para quê? Meias verdades da "reforma". Revista Retratos da Escola, Brasília, v. 11, n. 20, p. 33-44, jan./jun. 2017.

KÜENZER, A. Z. O Ensino Médio no plano nacional de educação 2011-2020: superando a década perdida? Educação e Sociedade, Campinas, v. 31, n. 112, p. 851-873, jul./set. 2010.

. A formação de professores para o Ensino Médio: velhos problemas, novos desafios. Educação e Sociedade, Campinas, v. 32, n. 116, p. 667-688, jul./set. 2011.

MAINARDES, J. Reflexiones sobre el objeto de estudio de la política educacional. In: TELLO, C.; ALMEIDA, M. L. P. Los objetos de estudio en política educacional. Hacia uma caracterización del 
campo teórico. Buenos Aires: Editorial Autores Argentinos, 2014.

MASSON, G. A valorização dos professores e a educação básica nos estados. Revista Retratos da Escola, Brasília, v. 10, p. 157-174, 2016.

MORAES, C. S. V. O ensino médio e as comparações internacionais: Brasil, Inglaterra e Finlândia. Educação e Sociedade, Campinas, v. 38, nº 139, p. 405-429, abr./set. 2017.

MOTTA, V. C. da; FRIGOTTO, G. Por que a urgência da reforma do ensino médio? Medida Provisória $\mathrm{n}^{\circ}$ 746/2016 (lei no 13.415/2017). Educação e Sociedade, Campinas, v. 38, nº. 139, p. 355-372, abr.jun. 2017.

OLIVEIRA, D. A. Regulação Educativa na América Latina: repercussões sobre a identidade dos trabalhadores docentes. Educação em Revista (UFMG), v. 44, p. 209-227, 2006.

. O Ensino Médio perante a obrigatoriedade ampliada: que lições podemos tirar de experiências observadas? Revista Brasileira de Estudos Pedagógicos, Brasília, v. 91, p. 10-26, 2010.

Os docentes no Plano Nacional de Educação: entre a valorização e a desprofissionalização. Revista Retratos da Escola, Brasília, v. 8, n. 15, p. 447-461, jul./dez. 2014.

Carreira e piso nacional salarial para profissionais da educação básica. Revista Retratos da Escola, Brasília, v. 10, p. 121-140, 2016.

OLIVEIRA, D. A.; ASSUNÇÃO, A. A. Condições de trabalho docente. Belo Horizonte: GESTRADO/FAE/ UFMG, 2010 (Verbete).

PINTO, J.M.R. O que explica a falta de professores nas escolas brasileiras? Jornal de Políticas Educacionais, v. 9, p. 3, 2014.

PINTO, M. N.; DUARTE, A.; VIEIRA, L. M. F. O trabalho docente na educação infantil pública de Belo Horizonte. Revista Brasileira de Educação (Impresso), v. 17, p. 611-626, 2012.

SAVIANI, D. Vicissitudes e perspectivas do direito à educação no Brasil: abordagem histórica e situação atual. Educação e Sociedade, Campinas, v. 34, n. 124, p. 743-760, jul./set. 2013.

Formação de professores no Brasil: dilemas e perspectivas. Poíesis Pedagógica - v.9, n.1, jan./jun. 2011.

SILVA, M. R. da. Direito à educação, universalização e qualidade: cenários da Educação Básica e da particularidade do Ensino Médio. Jornal de Políticas Educacionais, v. 9, p. 61-74, 2015.

Artigo recebido em: 05/09/2017 Aprovado em: 19/01/2018

Contato para correspondência: Gilvan Luiz Machado Costa

E-mail: gilvan.costa@unisul.br

1 As dimensões extraescolares e intraescolares conformam o conceito de educação com qualidade social. "As primeiras dizem respeito às condições socioeconômicas e culturais, dos direitos e das obrigações e garantias. As segundas referem-se a condições: a) de oferta, de gestão e organização do trabalho nas instituições educativas; b) de valorização, formação, profissionalização e ação pedagógica; c) de acesso, permanência e desempenho escolar e acadêmico" (FÓRUM NACIONAL DE EDUCAÇÃO, 2017, p. 19). 
2 Formação que permita aos jovens "entender ampla e criticamente tanto a sociedade em que vivem quanto a forma pela qual se estrutura o trabalho que realizam, tendo em vista a construção de formas mais humanas e igualitárias de produzir e viver" (KRAWCZYK; FERRETTI, 2017, p. 40).

3 Com base em Oliveira e Assunção (2010), a noção de condições de trabalho designa o conjunto de recursos que possibilitam a realização do trabalho do professor, envolvendo as instalações físicas, os materiais e insumos disponíveis, os equipamentos e meios de realização das atividades pedagógicas. Envolve também, no âmbito das relações de emprego, elementos concernentes à carreira docente, com destaque ao vínculo, à remuneração e à jornada de trabalho.

4 O foco deste trabalho é analisar aspectos da valorização dos professores das escolas estaduais, que constituem a maioria nesta etapa da Educação Básica.

5 Inclui cursos de complementação pedagógica.

6 Aproximadamente 7\% apresentam como escolaridade máxima o Ensino Médio.

$7 \quad$ Para Pinto (2014), com exceção da disciplina de Física, existem professores habilitados em número mais do que suficiente para assumir as turmas existentes, concluindo-se que se trata essencialmente de um problema de falta de atratividade da carreira docente.

8 "Assegurar, no prazo de dois anos, a existência de planos de carreira para os (as) profissionais da educação básica e superior pública de todos os sistemas de ensino e, para o plano de carreira dos (as) profissionais da educação básica pública, tomar como referência o piso salarial nacional profissional, definido em lei federal, nos termos do inciso VIII do art. 206 da Constituição Federal" (BRASIL, 2014).

9 Para Oliveira (2006), a intensificação do trabalho docente resulta da ampliação da jornada de trabalho e do aumento considerável de responsabilidades que os docentes tiveram com as reformas mais recentes. Com base na autora, a intensificação do trabalho docente pode ser intensa, com a ampliação das funções/tarefas e/ou extensa com a ampliação da jornada de trabalho. 